\title{
Research on Criteria for Operational Audit of Expenditure from State Budget in Vietnam
}

\author{
Thi Thu Huyen Vu Thi Duyen Luu \\ Thuongmai University, Vietnam \\ Thi Hue Dang \& Thi Dieu Thu Nguyen \\ University of Transport Technology, Vietnam \\ Manh Dung Tran \\ National Economics University, Vietnam
}

\begin{abstract}
In Vietnam, operational audits have been upgraded as an independent form of audit in the operation of the supreme audit agency. However, because it was introduced later than other types of audit, it is still confusing and general in setting criteria of audit. There are no specific guidelines for auditing expenditure from state budget. Therefore, the formation and application of audit criteria in the audit practice of expenditure from state budget has not been effective, spontaneous and influenced by the actual capacity of assigned auditors. Meanwhile, in order to perform the proper audit function, the most important thing is to build up the evaluation criteria. Based on data collected both secondary and primary from interviewing auditors, experts in the field of state budget, we conducted the synthesis, analysis, evaluation, comparison and clarification of research issues. The results show that the formation of audit criteria is not really reasonable; criteria for economic efficiency and effectiveness are sometimes unclear. Therefore, this study is to identify and develop criteria for evaluating the operational audit of expenditure from state budget in Vietnam.
\end{abstract}

Keywords: Criteria, economy, efficiency, effectiveness, operational audit.

DOI: $10.7176 /$ RJFA/10-10-18

Publication date:May $31^{\text {st }} 2019$

\section{Introduction}

Although research on criteria for operational audit in general has been publicized in many studies and reports, the level of evaluation of expenditure from the state budget is still different and the amount of provided information is limited, not identical due to different sources of data.

In recent years, the criteria for operational audit in general and the operational audit criteria for expenditure from the state budget have attracted interest from experts, but there are not many research projects and there are still many debates that need to be discussed and studied for clarification. In order to contribute to improving the efficiency of the State Budget in a transparent manner, improving the economy, effectiveness and efficiency of budget spending, the role of auditing budget spending by the State Audit of Vietnam has become increasingly important in the current period.

The assessment of the economic efficiency and effectiveness of activities in ministries is carried out at a very modest level, initially implemented in small theme audits. The implementation of audits in these units still focuses mainly on auditing the budget, confirming the annual financial statement data; assessing the law compliance, complying with the process of the State budget application. Another reason why the operational audit of budget expenditure in ministries in Vietnam is still limited is due to lack of standards and criteria for evaluating economic, efficiency and effectiveness.

Besides, the total actual budget expenditure in Vietnam has increased year by year, the size of the following year's budget spending is higher than the previous year. For regular spending on the budget, the average growth rate for the period 2012-2017 was 17\% per year on average. Of which, the largest proportion was for education and vocational training, accounting for $38 \%$, administrative management expenditure accounted for $23 \%$, and health care expenditure accounted for 12\%. In the period 2013-2018, the proportion of spending on development investment was estimated an average of $18 \%$ of total state budget expenditure. Thus, budget spending in Vietnam is constantly high, causing a budget deficit, threatening the sustainability of the state budget. In the context of the current economic situation facing many difficulties, the budget revenue is tightened, with the determination to improve the quality and efficiency of investment from the state budget capital; State Audit of Vietnam needs to carry out operational audits on spending from state budget to make recommendations to improve the current situation.

According to Ministry of Finance (2016), 1,968 projects (using state budget capital) were postponed, delayed the implementation plan and schedule, with a total capital of 5,991 billion Vietnamese dong (VND). In 2017, the total expenditure for development investment reached 78,975 billion VND, equal to $70 \%$ of the estimate, $8.8 \%$ 
higher compared to 2016. The number of completed projects approved for settlement was 16,883 , with a capital of 30,973.8 billion VND. In 2018, the volume of investment capital implementation from the state budget reached over 106.12 billion VND, equal to $82.7 \%$ of the annual plan, as well as bidding for construction investment was strictly implemented, contributing to saving 1,762.61 billion VND, in which central agencies saved 455.74 billion VND and provinces and cities saved 1,306.87 billion VND. Therefore, it is necessary to have specific evaluation criteria for state budget spending in Vietnam in the current period.

\section{Literature Review}

The supreme auditing agencies in the world still do not have a unified concept of the operational audit, the concept of evaluation criteria as well as the concept of economy, effectiveness, and efficiency (3Es).

Glynn (1993) believed that auditing money value can be considered to include three factors: economy, effectiveness and efficiency. The first two factors are relatively controversial, but the third factor 'efficiency' is difficult to identify and measure. Examining the effectiveness of activities using budget capital is related to the implementation of the government's political goals. INTOSAI (2007) argued that audit the operational economy involving expenditure should comply with principles and practice of budgets as well as appropriate management policies. In addition, the audit of operational efficiency is related to achieving the objectives of auditee and auditing the actual impacts of activities compared to the expected impacts.

Auditing criteria in operational audit involves emphasizing aspects or operational measures that an auditor uses to evaluate an issue. It is a set of standards that are reasonable and achievable in terms of unit performance so that the economy, efficiency and effectiveness of activities can be assessed.

Thus, "criteria" can be interpreted as a standard, a rule or an experiment to evaluate an object or a problem. It is impossible to have a general criterion for all auditing operations, but auditors must set up a set of separate audit criteria for each type of audit.

Determining the criteria for evaluating the economy, effectiveness and efficiency in an audit essentially refers to determining the evaluation criteria to perform a certain operational audit.

\section{Economy}

Economy is defined as the economical use of input resources to achieve the set objectives.

Many studies states that economy is closely linked to the effectiveness in the practice of public sector audits. According to McCrae et al. (1997), Nath et al. (2011) the input factor should be considered in terms of both economy and efficiency. On the other hand, it is difficult to assess and measure separately economy and efficiency of one activity due to the interdependence between these two objectives. Dittenhofer's study (2002), Chapman (2007) argues that economy is closely linked to the effectiveness of public sector audits. According to Nath et al. (2011), there are many explanations regarding the economy in operational auditing, but the purpose and meaning of the economy has not been adequately studied.

\section{Efficiency}

Efficiency appears when the number of products or services is produced the most efficiently from certain resources or using the minimum resources to achieve the target of quantity and quality of particular products and services. Therefore, the audit of efficiency needs to check and compare the cost (input) with the result (output).

In fact, the distinction between economy and efficiency is rarely clear. Therefore, in the process of conducting operational audits, auditors need to consider different combined aspects, especially when considering the close linkages between the economy and efficiency.

The authors who study the theory of operational audit in public units such as Glynn (1993), McCrae \& Vada (1997), believe that efficiency includes the economy regardless of the difference between economy and efficiency. The main purpose of management is to maximize output with constant resources.

\section{Effectiveness}

Effectiveness indicates the accomplishment level of the objectives of the operation. According to Glynn (1993) and Nath et al. (2011), effectiveness relates to the success, the level of results achieved or the desired goal of the public entity. In addition, the effectiveness also studies the relationship between output and objectives of public units. Therefore, auditors can focus on the objectives of the unit and measure how the output has contributed to achieving the goal of the organization.

The economy, efficiency and effectiveness have a close relationship, reflecting the unity in the whole process of operation. Efficiency is a relative concept, determined on the basis of a comparison of costs (inputs) and products and services (outputs), so the concepts of efficiency and economy cannot be separated. Economical use of resources (minimizing input costs) will contribute to ensuring efficiency. On the other hand, effectiveness is both independent and closely related with efficiency because it is impossible to have an effective operation if it does not achieve its objectives or cannot achieve its purpose at any price. 


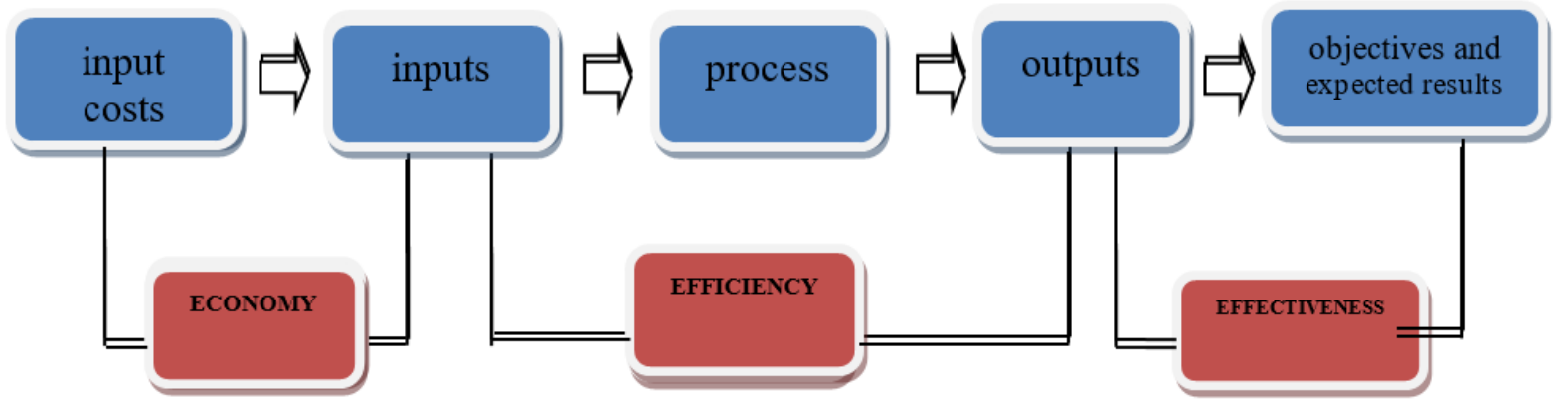

Diagram 1: The relationship between the principles of economy, efficiency and effectiveness

Based on the above analysis, it is possible to generalize the approach of assessing the economy, efficiency, effectiveness when the operational audit is based on the process in the diagram 2.

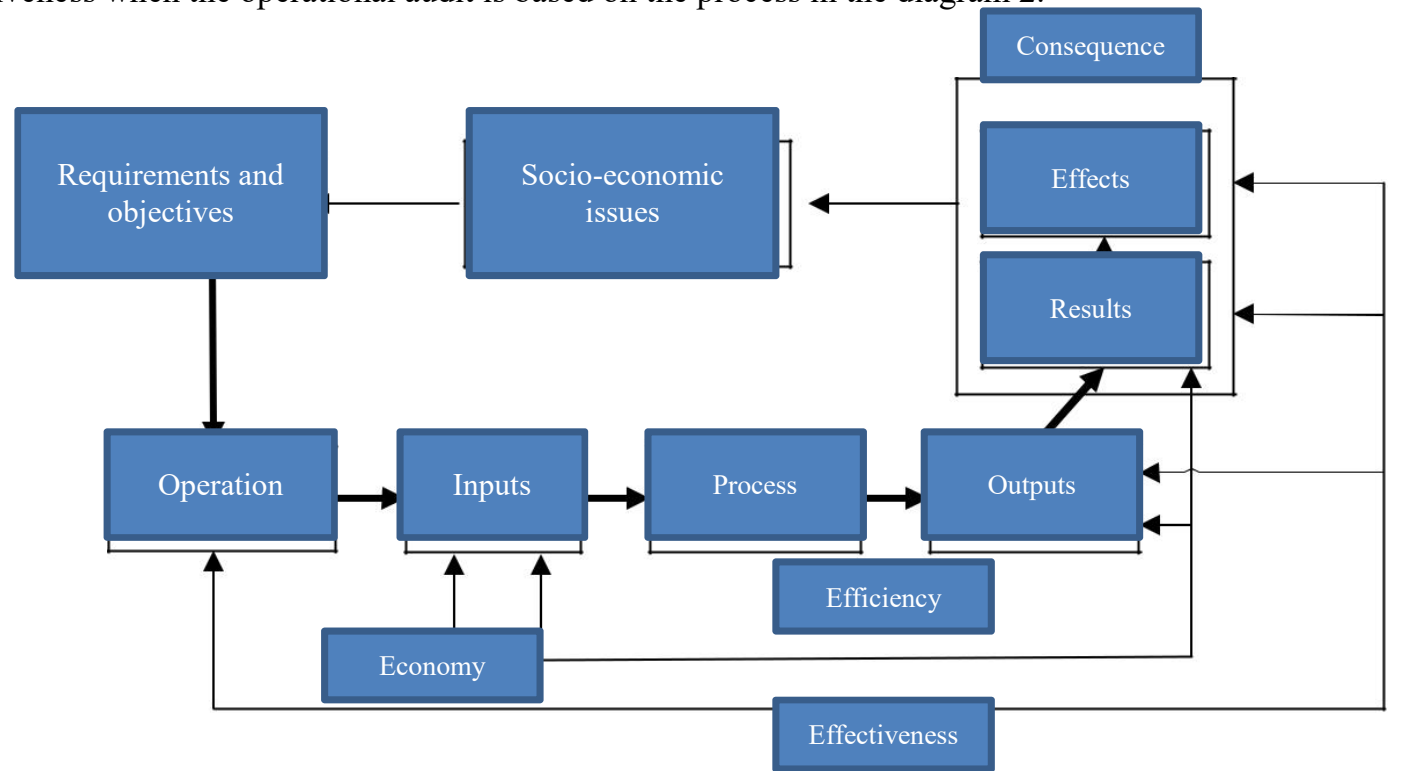

Diagram 2: Approach model to assess the economy, efficiency and effectiveness when conducting operational audit

\section{Research Methodology}

This study focuses on studying criteria for evaluating operational audits for expenditures from the state budget in ministries carried out by the State Audit of Vietnam (SAV). This audit was carried out from 2015 to 2018 related to spending from the State Budget.

In which the qualitative research method to survey and explore audit criteria is combined with data collection methods such as (i) Collect data from documents, audit reports, field surveys and in-depth interviews with experts; (ii) Analyze and discuss survey results; and (iii) Discover and synthesize the criteria for auditing expenditure from the state budget.

Secondary data: statistically conduct case studies related to the article, point out new points in previous studies; collect and study the research results of domestic and foreign scientists related to the article, thereby determining the audit criteria.

Primary data: collect materials through methods such as sending survey questionnaires, direct interviews.

To implement the method, we has designed survey questionnaires including closed-type questions and openended questions to send to State audit leaders, leaders and auditors of the SAV at the audit departments of specialized audits II, III, general department, regime and quality control department, the legal department of SAV involved in the operational audit of spending from the state budget capital;

Develop an open-ended Questionnaire to discuss directly with the SAV's leaders, directors and auditors at the audit departments of the Audit II, III; The Department of General Affairs, quality control department, Department of Legal Affairs of the SAV who have participated in the operational audit of spending from the state budget.

Develop open questionnaires to exchange directly with auditors at specialized audit departments II, III, and audit departments operating under the General Department.

Conducting interviews, direct exchanges of related subjects, interviewing policy experts, auditors. Consulting experts to clarify the research criteria, as a basis for giving more conclusive conclusions and orientations to build 
auditing criteria for spending activities in the state budget in the coming time.

\section{Results and Discussion}

Results of audit report collection, in-depth interviews with executives and audit team leaders; we found that while conducting audits and evaluating operational efficiency at these units, auditors mainly use financial analysis indicators to describe and compare with previous fiscal years. This analysis and evaluation are not consistent and synchronous between the budget users.

\subsection{Economy Criteria}

The criteria of economy while conducting the operational audit of spending from the state budget capital are usually carried out by the auditors who compare the total expenditure estimates and the level of expenditures according to the settlements at the ministries and the spending levels according to the settlement of regular spending activities and development investment expenditures. Based on the estimated figures and settlement figures of the ministries and auditors conduct the table of assessment on the difference in the estimates and settlement of expenditures from the state budget and the difference will be evaluated.

In each ministry, with each specific activity, the auditor compares the cost savings of each specific activity by comparing the difference of actual expenditures against the approved estimates to determine the level of cost savings of each activity: regular spending and development investment expenditures.

However, the level of expenditure from the budget for each activity in the ministries is different, depending on the functions and tasks of the Ministry. Therefore, the criteria for assessing the economy of each ministry are different; Economy criteria are evaluated as economical when the performance target of that expenditure is lower than the plan and estimate. Based on the data of difference, the auditors concludes on the saving level of the operation, finding out the reason for this to have an appropriate audit recommendation.

\subsection{Efficiency Criteria}

Auditors evaluate the efficiency of budget spending through analyzing and assessing the structure of expenditure sources for budget spending activities in the ministry.

At the same time, through determining the criteria below and assessing based on the achieved, partially achieved or not achieved criteria. However, the scale to assess the level of attainment, partial or unsuccessful achievement is still subjective of the auditors and the audit team but not yet sufficient.

* Criteria for the auditors to assess the efficiency in using and managing expenditures from the state budget in the ministries

- Are the classified expenditures from the state budget capital in the Ministries properly implemented for the right purpose? Has the content been properly regulated in the budget management decentralization yet?

- Does the financial resources in the Ministry prioritize the needs or objectives of the Ministry in terms of financial tightening (reducing recurrent expenditures)?

- Is there any limit on administrative costs, improving the autonomy of the subordinate to the lower-level estimating units, creating motivation to save costs by specific ways?

- Does the service quality increase when the decision to spend in the direction of reducing regular expenditures (autonomy in some units of the Ministry, the administration of administrative costs, the reduction of civil servants.)? - Has the increased accountability of lower-level estimating units in the use of budget spending been implemented?

* Criteria for auditors to evaluate the efficiency of the Ministry's budget spending process

- Is the budget estimation (budget revenue and expenditure estimation) effective?

- Does the budget comply with the budget plan?

- Is the budget accounting honest and complete? Is the settlement data matching the documents?

- Regarding accountability for budget activities, is the budget decisions made with responsibility?

\subsection{Effectiveness Criteria}

Effectiveness of spending activities from the Budget in the Ministries is reflected in the level of achieving the objectives in the expenditure activities of the unit. Through interviews, the auditors found out that this criteria is a very difficult to assess specifically; it can be divided into the following two groups of criteria:

- Defining criteria: often reflected in the operational plan objectives or estimated in the ministry's work plan. Can auditors indicate spending activities, budget allocation, budget implementation with disbursement schedule?

- Estimating criteria: predicting the impact of future performance results of spending activities if implemented according to capital plans.

- Effectiveness is achieved when the Ministries strictly complies with the provisions of the State budget law, investment project items to ensure time schedule, contract conditions.

- Has the Ministry developed and followed the steps of the budget process?

- Do members perform the assigned functions properly? 
- Does the ministry implement the principles of control, assignment, division, assignment and authorization in budget spending activities?

* Criteria that auditors use to evaluate the effectiveness of internal control

- Does the ministry fulfill the objectives and plans related to the implementation of the Budget task?

- Does the ministry implement the control principles such as assignment, authorization, approval in management activities?

- Do the departments and members perform their assigned functions correctly?

The results of audit shows the legal effect of regulations on State management on regular expenditures, especially investment in capital construction, capital management and other related regulations issued by the State agency, investors and stakeholders fully comply with the implementation process. However, there are some shortcomings that partly reduce the validity of promulgated legal documents.

\subsection{Findings}

Based on the survey data from 2014-2018 the operational audit of state budget spending in ministries implemented by the State Audit of Vietnam, the authors found out that:

First, auditing criteria of the operational audit of spending from the state budget in the ministries have not been properly built. For the SAV, the operational audit is still a new concept and has no precedent, so the criteria have not been shaped, set up immediately when selecting the subject of auditing to orient and will definitely collect audit evidence to evaluate criteria; resulting in both working and adding criteria in the audit process, The constructed criteria are still primarily prognostic, qualitative has not much specific assessment in terms of quantitative.

Surveying and collecting information from the stage of selecting the auditing topic, the step of the audit planning step is not long enough, there is no effective support from the experts and the quality to establish criteria for evaluating economy, efficiency and effectiveness.

Some audit criteria have been established without consulting experts or opinions of audited units, leading to not fully understanding the operational objectives of the budget cycle, failing to correctly determine the audit objectives making the auditing criteria not yet close, not attached to the content according to 3Es and there are some cases where no agreement with the audited units and managing agencies are reached.

The results of auditing to assess the economy, efficiency, effectiveness of expenditures from the State budget have not met the requirements, not fully analyzed and evaluation of the criteria set in management, using resources, assessing the effectiveness of policies; The comments are general, no specific criteria for assessing each audit content; The quality of auditing has not satisfactorily answered the issues of efficiency of spending from the state budget, providing information to ministries and branches at all levels to improve the efficiency of decisions, supervision, management and regulation, Budget implementation, amending and supplementing more appropriate policy mechanisms.

Second, awareness, professional capacity and skills of Auditors in assessing the economy, efficiency and effectiveness are still limited in both theory and practical experience in setting appropriate auditing criteria due to this new type of audit conducted by the SAV. The auditors mainly use the skills of auditing financial statements, Compliance audit to make comments to evaluate the economy, efficiency and effectiveness of audits. On the other hand, the audit evaluating the economy, efficiency, effectiveness of management and use of state budget, public property of the State at the ministries is complicated due to difficult output of activities, programs and projects quantification and beyond economic efficiency are also socially effective.

Third, the department of performance audit has not actively informed the audited units about the main aspects of the audit, especially the audit criteria prior to the start of the data collection period and after completing an audit plan for coordination in the audit process and creating consensus on established audit criteria. Currently, only conferences are held to announce the audit decisions stating the objectives, the general content of the audit and the time period, the list of auditors performing the audit at the units.

Fourth, the determination of audit criteria to assess the economy, efficiency and effectiveness in expenditure from the state budget in auditing process in ministries is still widespread; while in the countries where the operational audit has developed, audit teams only choose 1-2 audit criteria to evaluate and comment. Basically, economy is the same as the efficiency, so sometimes there is no need to distinguish these two criteria and the efficiency criteria will decide, and affect the efficiency criteria.

The ambition to evaluate the whole economy, the effectiveness and efficiency of an audit is too vast considering both the theoretical and practical aspects of a particular audit, not necessarily trying by all means to conclusions on all three criteria of a management apparatus. The priority of any goal depends on the content of interest in the task of performing the function that the Ministry is undertaking, depending on the requirements of socio-economic development in each stage, as well as capacity and qualifications of Auditors

Fifth, the implementation of the audit to assess the economy, efficiency and effectiveness of management and use of the budget in auditing expenditures from the State budget capital should build up criteria for each audit 
objective. In fact, the criteria for making assessments, comments on the economy, efficiency and effectiveness of the State budget spending activities over the past time are mainly subjective of the Auditors on the basis of evidence collected and based on analysis and evaluation on the unit's Budget reports. The preparation of an audit report on the content of "economy, efficiency, effectiveness in management and use of state budget, money and national property" according to the regulation form. However, the content still lacks a convincing basis, mainly assessing and analyzing on the basis of the unit's reporting information and the content of the assessment also repeats the contents of other items.

\section{Recommendations for Improving Evaluation Criteria in Operational Audit}

Based on summaries of previous studies and surveying audit practices of some developed countries in developing audit criteria assessment; we noticed that $t \mathrm{t}$ is difficult to develop a uniform set of criteria to apply to all audits, in addition to the common goal to assess the economy, effectiveness and efficiency of implementing the Government's Resolutions on State budget, each ministry and branch has its role, position, specific organization of activities, models, and various operational tasks. Therefore, constructed criteria should be directed to spending activities from the State's main state budget to achieve the objective of implementing functional tasks as prescribed, in order to create the initiative for auditors when applying these criteria.

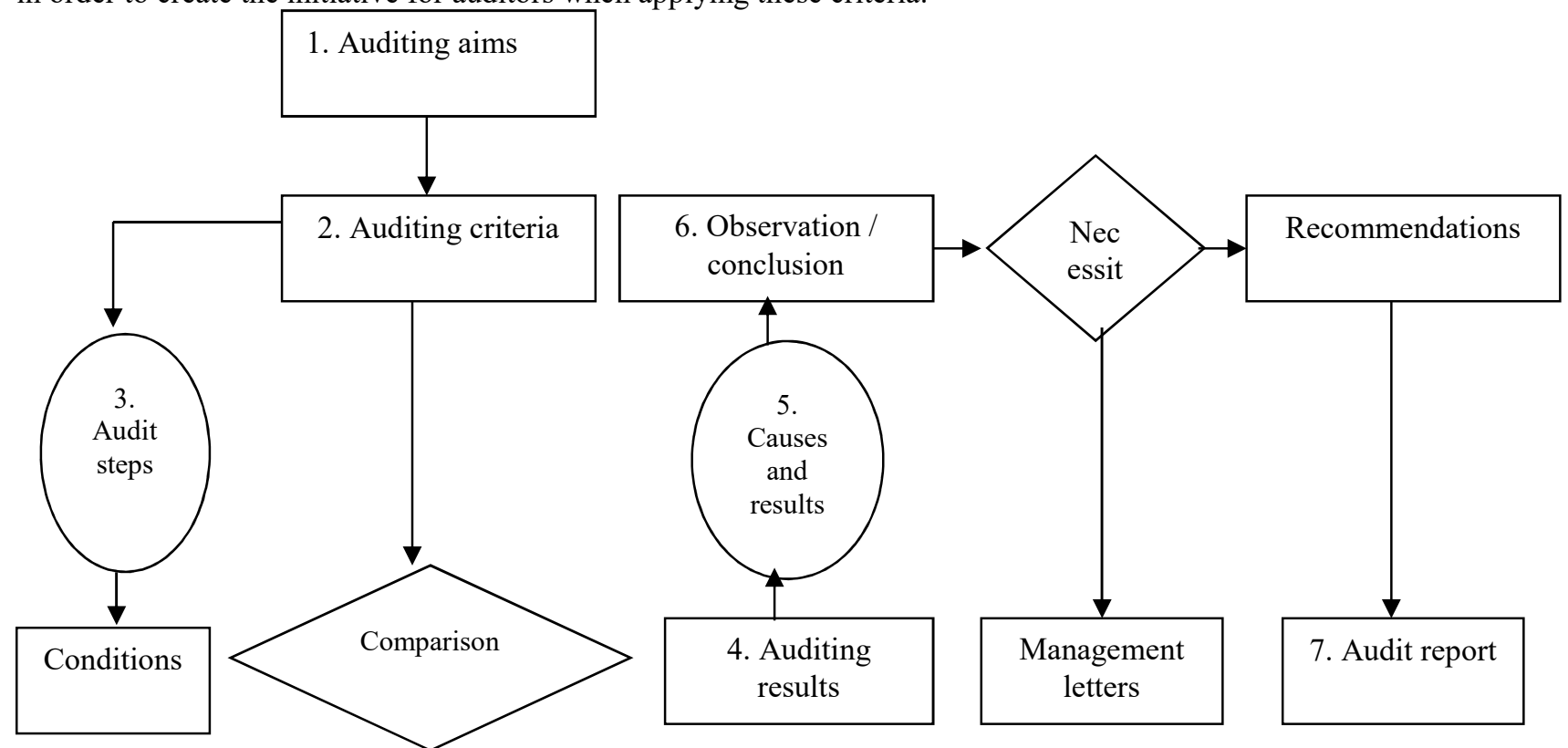

Diagram 3: Process of developing Auditing criteria

\subsection{Complete criteria for evaluating economy}

Economy shows the level of saving of inputs and still achieves the unit's operational objectives. For ministries that need to achieve state management goals with as little expenditure as possible, they still ensure acceptable quality. Budget expenditure savings $=$ Actual spending amount - expenditure approved on cost estimate Saving amount $<=0$ saved financial resources compared to estimates. Number of saving $>0$ wasted financial resources compared to the plan.

However, the assessment of savings depends on expanding the scale of operation, improving the quality of services, changing financial mechanisms and meeting the implementation of specialized functions of the ministry.

In order to develop the audit criteria, it is necessary to determine the purpose of use and the management of the financial resources of the unit. For ministerial-level administrative agencies, financial management is aimed at balancing spending needs and meeting the performance of assigned functions and tasks effectively.

a, Proposing criteria for economy calculation according to budget spending activities at the Ministry Auditors will provide information on the costs of regular spending and development investment, including:

- Regular spending includes Expenses for education and training; Spending for health and population; Expenses for Science and Technology; Economic career expenses; Expenditure for environmental protection; Administrative management expenditure

- Expenses for development investment include Expenses for evaluation and approval of total cost estimates; Expenditure for investment bidding; Expenses for investment implementation; Expenses for examination and approval of investment settlement.

Therefore, auditors compares these contents on the aspects: actual implementation, approved estimates and 
explanation of the reasons for differences, explaining the reasons for differences to make conclusions and audit recommendations.

$b$, Proposing a scale to assess the economy in spending activities from the state budget according to specific spending activities at the ministry, include:

- Directing the management of saving practice and reducing wastefulness (maximum score is 10).

- Specific results of saving total recurrent expenditure (except for wage and salary items) (maximum score is 40).

- Results of thrift practice and waste combat of the estimating units under the maximum scale of 40).

- Savings, inspection and waste prevention activities (maximum score is 10).

And then, auditors gave actual scores on these contents and explained the reasons for difference to make conclusions and audit recommendations.

\subsection{Complete criteria for evaluating effectiveness}

For the ministries, the efficiency of the total expenditure from the state budget needs to reach the available cost to achieve the higher the better. In addition, the goal is not only in relation to resource costs (financial, human resources...) but also in relation to social efficiency.

a, Criteria for assessing economic efficiency (in term of money)

It is the difference or comparative ratio between the total economic value obtained at the output (economic value brought about by the development investment expenditure) at the time of evaluation to determine the efficiency with the total input cost (multiplied by force, funding, materials, vehicle depreciation and facilities, energy, etc.).

The formula is:

Economic efficiency $=$ Total value, economic benefits obtained - Total costs (public spending for development investment)

If the total value of economic benefits is much greater than the investment spent, the economic efficiency is higher. $b$, Proposing criteria for auditing the effectiveness according to the function of budget spending at the Ministry according to 2 criteria: the ratio of regular expenditures and the ratio of investment expenditures according to the approved estimates and actual implementation. And then, making audit conclusions and recommendations to the unit.

In which:

Regular spending rate $=$ Total regular spending/Total spending from state budget at each ministry. The rate of spending on development investment $=$ Total investment expenditure/Total spending from state budget at each ministry

In the operational audit of spending from the state budget, the economy for regular spending (savings) is highly appreciated, while in the investment in development, the efficiency is always mentioned and focused.

$c$, Evaluate the efficiency of investment spending according to the achieved outcomes

For operational auditing, it is very important to set up the operation model of the object, different from the other type of audit and is the key to build appropriate criteria. Auditors need to communicate with the unit to reach the maximum consensus on operational modeling.
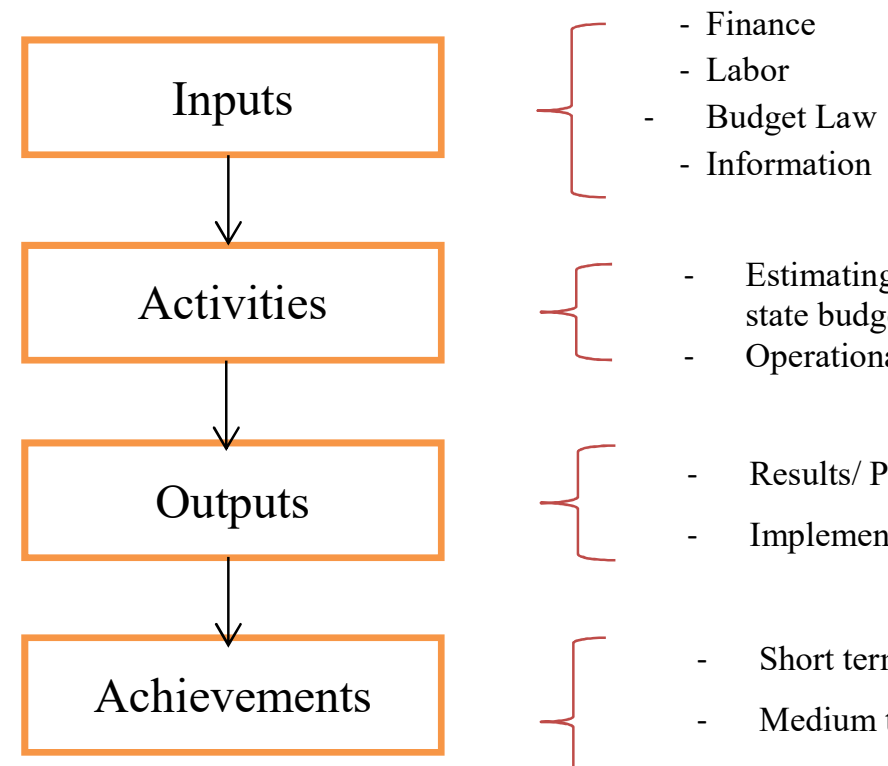

- Estimating activities, estimates and settling the state budget

- Operational processes

- $\quad$ Results/ Process of Budget spending

- Implementation

- $\quad$ Short term

- $\quad$ Medium term

- $\quad$ Long term

Diagram 4: Developing a model of spending activities from the state budget 
Based on the budget expenditure operation model, the auditors create a table to assess the effectiveness of spending from the state budget according to the output results to assess the economic and social efficiency of spending activities. Assessing the efficiency of spending from the state budget according to the output depends on the functions and tasks of each ministry, to create output products, results and investment spending efficiency accordingly.

\subsection{Completing criteria for evaluating effectiveness}

Effectiveness shows the level of achieving the objectives in the operation of the unit. Evaluating the accomplishment of an activity goal. Thus, for the typical budget expenditure audit, it is necessary to develop the criteria for evaluating the effectiveness as follows:

a, Develop criteria to evaluate the effectiveness of managing the budget expenditure activities of the ministry on the evaluation contents. It includes Skills of budget estimation; Budget estimation process; Implementing techniques for budget estimation; Skills of budget settlement; Organize meetings to implement budget activities. Based on that the auditors compare these contents on the following aspects: actual performance, assigned targets and explaining the causes of differences, explaining the reasons for difference to make conclusions and audit recommendations.

$b$, Develop criteria for evaluating the effectiveness of issuing policies and legal documents related to the Ministry's budget on the following contents: The process of developing legal documents of the Ministry of finance and investment as prescribed; Obtaining opinions of estimating units under draft legal documents; The promulgated legal documents have met the practical needs and objectives of budget management at the Ministry.

And then, the auditors compare these contents on the following aspects: actual implementation, assigned targets and explain the causes for differences, explain the reasons for differences to make conclusions and audit recommendations.

$c$, Develop criteria for auditing the effectiveness of operational management to increase operational efficiency by the following criteria: Rate of cost optimization of operations; Rate of completion of spending from the state budget; Progress of putting key investment projects into operation.

$d$, Develop criteria for evaluating the effectiveness of accountability of the Ministries on budget spending.

Accountability is one of the requirements of good administration. Agencies and public employees must be accountable for their activities. Accountability is not only done with higher levels but also with external audiences (organizations, citizens, businesses) when they use public services created by the ministry, provided and responsible for the consequences of the unit. Criteria for accountability of budget spending need to assess the following activities: Explain to the authorities about law enforcement, comply with regulations issued by superiors; Explain to the legislative bodies the implementation of the functions and duties assigned; Ability to answer questions and inquiries for use of administrative services; Respond to mass media agencies on issues related to their public responsibility.

\section{References}

Chapman, S. (2007), Emerging Issues and Global Challenges in Public Sector Audit in the $21^{\text {st }}$ Century. Paper presented to National seminar on Public Sector Audit: Enhancing Transparency and Accountability in the Management of State Finance, Jakarta- Indonesia.

Dittenhofer, M.A. (2002), Performance Auditing for Government Financial Management. Florida: International Consortium for Government Financial Management.

Glynn, J. J.(1993), The development of Performance Auditing in Australia, Paper presented at the Annual Research Lecture in Government Accounting, Australian Society of Accountants.

McCrae, M., \& Vada, H. (1997), Performance Audit Scope and the Independence of the Australian Commonwealth Auditor-General, Financial Accountability \&Management, 13(3), 203-223.

Nath, N., Peursem K.V. \& Lowe, A. (2011), Public Sector Performance Auditing: Emergence, Purpose and Meaning. Working paper series Number 81, New Zealand, The University of Waikato.

INTOSAI (2007), Building Capacity in Supreme Audit Institution, UK National Office, Edition 1, 2007. 